\title{
Analisis komoditas unggulan agribisnis dan pengembangannya pada sentra produksi Kota Sungai Penuh
}

\author{
Sesraria Yuvanda \\ Fakultas Ekonomi dan Bisnis Universitas Muhammadiyah Jambi \\ *E-mail korespodensi: sesra.umjambi@gmail.com
}

\begin{abstract}
This study aims to determine the selected agribusiness commodities to be developed and analyze the production and marketing for current and future conditions. The Simple Additive Weighting (SAW) model is used to determine the only things of agribusiness, while the analysis of production and marketing development uses a qualitative descriptive analysis model. The results showed that the selected superior commodities were Chili with the first rank, Coffee in the second rank, Cinnamon in the third rank, and Potato in the fourth rank. Production and marketing conditions now show no increase in added value and the role of cooperatives. Production and marketing in the future that is desired must increase added value and market control through cooperatives.
\end{abstract}

Keywords: Excellence, Agribusiness, Marketing

\begin{abstract}
Abstrak
Penelitian ini bertujuan untuk menentukan komoditas unggulan agribisnis terpilih untuk dikembangkan dan menganalisis produksi dan pemasaran komoditas agribisnis terpilih untuk kondisi sekarang dan masa ke depan. Untuk menentukan komoditas unggulan agribisnis tersebut digunakan model Simple Additive Weighting (SAW) sedangkan analisis pengembangan produksi dan pemasaran digunakan model analisis deskriptif kualitatif. Hasil penelitian menunjukkan bahwa komoditas unggulan terpilih adalah Cabe ranking pertama, Kopi ranking kedua, Kayu Manis ranking Ketiga dan Kentang ranking yang keempat. Produksi dan pemasaran kondisi sekarang terlihat petani perkebunan maupun holtikultura tidak ada peningkatan nilai tambah dan peran koperasi. Produksi dan pemasaran ke depan yang diinginkan harus terjadi peningkatan nilai tambah dan penguasaan pasar melalui koperasi.
\end{abstract}

Kata kunci : Unggulan, Agribisnis, Pemasaran

\section{PENDAHULUAN}

Pengembangan ekonomi suatu daerah merupakan proses dimana adanya interaksi antar pemerintah daerah dengan masyarakat dalam upaya mengembangkan sumber daya yang dimiliki sehingga membentuk pola kemitraan yang dapat menciptakan lapangan pekerjaan (Arsyad, 2005). Salah satu bentuk Pengembangan ekonomi daerah tersebut adalah pengembangan komoditas unggulan daerah.

Komoditas unggulan agribisnis pada sentra produksi berdampak terhadap peningkatan pendapatan petani dan sekaligus peningkatan produksi komoditas agribisnis untuk pemenuhan masyarakat kota maupun di luar kota. Watimin dan Putri, $\mathrm{H}$ (2016), pengembangan komoditas andalan pada komoditas agropolitan menjadi sangat penting untuk dilakukan untuk menilai keunggulan komperatif dari komoditas yang terpilih dan berdampak bagi petani.

Sentra produksi komoditas agribisnis di Kota Sungai Penuh menghasilkan komoditas berupa komoditas perkebunan dan komoditas holtikultura. Komoditas 
perkebunan yang dihasilkan petani di sentra produksi Kota Sungai Penuh berupa kayu manis dan kopi. Sedangkan komoditas hortikultura berupa kentang dan cabe. Harinta, dkk (2018), usaha peningkatan hortikultura yang unggul akan meningkatkan arus pendapatan kedaerah tersebut, meningkatkan konsumsi, meningkatkan permintaan produk.

Pada sentra produksi petani kayu manis didapati 462 orang dan 313 orang petani kopi dengan menghasilkan 55 ton kayu manis dan 12 ton kopi perbulan. Untuk komoditas holtikultura 119 petani kentang dan 253 orang petani cabe dengan produksi sebesar 38 ton kentang dan 13 ton cabe Perbulan.

Produksi komoditas perkebunan dan holtikultura tersebut dipasarkan di Kota Sungai Penuh dan Kota di luar Sungai Penuh seperti Provinsi Sumatera Barat dan Provinsi Jambi. Pemasaran komoditas perkebunan melibatkan pedagang penggumpul di Kota Sungai Penuh dan eksportir di Kota Padang. Sedangkan komoditas holtikultura melibatkan pedagang penggumpul dan pedagang besar di Provinsi Sumatera Barat dan Provinsi Jambi.

Sentra produksi komoditas perkebunan dan holtikultura di Sungai Penuh terdapat di Renah Kayu Embun. Kawasan tersebut terletak pada ketinggian 1200-1700 mdpl, dengan suhu rata-rata pertahun $19^{\circ} \mathrm{C}$. Kawasan ini sangat ideal untuk komoditas agribisnis untuk pengembangan komoditas agribisnis. Pengembangan komoditas perkebunannya sudah beradaptasi ekspor. Sedangkan komoditas holtikulturanya dipasarkan untuk memenuhi Kota Sungai Penuh sendiri dan Kota-kota yang ada di Provinsi Sumatera Barat dan Provins Jambi.

Untuk pengembangan komoditas agribisnis dari perkebunan dan holtikultura tersebut perlu dilakukan penelitian untuk menentukan komoditas unggulan dari agribisnis komoditas perkebunan dan holtikultura yang terdapat disentra produksi Kota Sungai Penuh. Di samping itu, juga perlu penelitian yang lebih mendetail untuk menganalisis kondisi pemasaran sekarang dan masa depan.

Sedangkan yang menjadi tujuan dari penyusunan kajian pengembangan Renah Kayu Embun menjadi kawasan agropolitan yang berkelanjutan di Kota Sungai Penuh adalah:1).Menentukan komoditas unggulan agribisnis terpilih untuk ditumbuhkembangkan. 2).Menganalisis pengembangan produksi dan pemasaran komoditas unggulan agribisnis terpilh.

\section{METODE}

Metode penelitian yang digunakan adalah metode analisis data primer dan metode observasi. Sedangkan Data yang dipakai dalam penelitian ini dikumpulkan melalui: Data Primer dan Data Sekunder. Data ini dikumpulkan melalui publikasi instansi terkait khususnya Organisasi Perangkat Daerah kota Sungai Penuh.

Untuk menjawab tujuan penelitian pertama, maka dipakai model analisis Simple Additive Weighting (SAW). Metode ini juga digunakan Yuvanda, S dan Aisyah (2021) untuk menentukan industri kecil pangan unggulan dimana komoditas kopi yang menjadi unggulan untuk provinsi Jambi. Model analisis ini membantu menentukan komoditas unggulan agribisnis.

Dimana:

$$
R_{i j}=\left\{\begin{array}{l}
\frac{X_{i j}}{\operatorname{Max} X_{i j}} \\
\frac{\operatorname{Min} X_{i j}}{X_{i j}}
\end{array}\right.
$$

$\mathrm{R}_{\mathrm{ij}} \quad=$ Matriks kinerja normalisasi

$\operatorname{Max} \mathrm{X}_{\mathrm{ij}}=$ Nilai maksimum setiap pilihan

Min $X_{\mathrm{ij}}=$ Nilai minimum setiap pilihan 
Adapun langkah penentuan komoditas unggulan pertanian dari model analisis yang dipakai adalah: 1).Penentuan kriteria dan pembobotan, 2).Penentuan nilai setiap alternatif komoditas unggulan agribisnis, 3).Perlakuan normalisasi matrik dengan formula.

Pengambilan keputusan ranking komoditas unggulan agribisnis adalah penjumlahan dari perkalian matrik ternormalisasi dengan vektor bobot dari kriterian yang dipakai;

$$
V_{i}=\sum_{j=1}^{n} W_{j} R_{i j}
$$

Dimana:

$\mathrm{V}_{\mathrm{i}} \quad=$ Nilai akhir alternatif

$\mathrm{W}_{\mathrm{j}} \quad=$ Nilai bobot kriteria

$\mathrm{R}_{\mathrm{ij}} \quad=$ Matrik kinerja normalisasi

$\mathrm{a}_{0} \quad=$ Intercept

$\mathrm{a}_{1}-\mathrm{a}_{5}=$ Koefisien regresi

Untuk menjawab tujuan penelitian kedua, digunakan deskriptif kualitatif terhadapt input produksi hingga output yang dipasarkan.

Lokasi penelitian ini dilaksanakan pada Sentra agribisnis Kota Sungai Penuh. Sentra agribisnis tersebut memproduksi kayu manis dan kopi untuk komoditas perkebunan serta kentang dan cabe untuk komoditas hortikultura.

\section{HASIL DAN PEMBAHASAN}

\section{Penentuan komoditas unggulan agribisnis terpilih}

Penentuan komoditas unggulan agribisnis dipakai model SAW (simple additive weighting). Keunggulan menggunakan model SAW ini dapat menentukan nilai berdasarkan ktiteria dan bobot dari alternative yang telah ditentukan (Kusamadewi, dkk, 2006). Dalam memakai model SAW tersebut dilaksanakan melalui 4 langkah penentuan komoditas unggulan agribisnis. Adapun keempat langkah tersebut adalah:

\section{Penentuan kriteria dan pembobotan}

Dalam menentukan komoditas unggulan agribisnis dipakai 4 kriteria. Kelima kriteria tersebut yaitu Petani, produksi, investasi, dan kapasitas. Bobot dari kelima kriteria dimaksud dipaparkan pada tabel di bawah ini.

Tabel 1. Bobot kriteria penentuan komoditas unggulan agribisnis

\begin{tabular}{clcc}
\hline No & \multicolumn{1}{r}{ Kriteria } & Kode & Bobot \\
\hline 1 & Petani & C. 1 & 0,233 \\
2 & Produksi & C. 2 & 0,333 \\
3 & Investasi & C. 3 & 0,167 \\
4 & Kapasitas & C. 4 & 0,267 \\
\hline
\end{tabular}

Sumber: Data diolah, 2021

Penentuan nilai setiap alternatif komoditas unggulan agribisnis

Mengacu kepada 4 kriteria yang bobotnya telah ditetapkan dilaksanakan penetapan nilai setiap alternatif dari komoditas unggulan agribisnis. Adapun hasil penetapan nilai alternatif tersebut dipaparkan pada tabel di bawah ini. 
Tabel 2. Nilai setiap komoditas unggulan agribisnis

\begin{tabular}{llcccc}
\hline No & $\begin{array}{c}\text { Komoditas } \\
\text { Unggulan }\end{array}$ & $\begin{array}{c}\text { Petani } \\
\text { (orang) }\end{array}$ & $\begin{array}{c}\text { Produksi } \\
\text { (ton) }\end{array}$ & $\begin{array}{c}\text { Kapasitas } \\
\text { (ton) }\end{array}$ & $\begin{array}{c}\text { Investasi } \\
\text { (juta) }\end{array}$ \\
\cline { 3 - 6 } & & C1 & C2 & C3 & C4 \\
\hline 1 & Kayu manis & 462 & 55 & 155 & 43 \\
2 & Kopi & 313 & 12 & 52 & 58 \\
3 & Kentang & 119 & 38 & 105 & 37 \\
4 & Cabe & 253 & 13 & 41 & 6 \\
\hline
\end{tabular}

Sumber: Data diolah, 2021

\section{Perlakuan normalisasi matrik}

Hasil penetapan nilai setiap pilihan komoditas unggulan agribisnis dilaksanakan normalisasi terhadap matrik hasilnya. Matrik ternormalisasi komodtas unggulan agribisnis disajikan pada tabel di bawah ini.

Tabel 3. Matrik ternormalisasi komoditas unggulan agribisnis

\begin{tabular}{clcccc}
\hline No & $\begin{array}{c}\text { Komoditas } \\
\text { Unggulan }\end{array}$ & C1 & C2 & C3 & C4 \\
\hline 1 & Kayu manis & 1,027 & 1,100 & 1,033 & 0,782 \\
2 & Kopi & 0,696 & 0,240 & 0,347 & 1,055 \\
3 & Kentang & 0,264 & 0,760 & 0,700 & 0,673 \\
4 & Cabe & 0,562 & 0,260 & 0,273 & 0,109 \\
\hline
\end{tabular}

Sumber: Data diolah, 2021

\section{Pengambilan keputusan ranking komoditas unggulan agribisnis}

Pengambilan keputusan guna penetapan komoditas unggulan agribisnis dilaksanakan dengan mengkalikan hasil matrik ternormalisasikan dengan vektor bobot kriteria yang dipakai untuk penentuan produk unggulan. Matrik hasil perkalian tersebut dipaparkan pada tabel di bawah ini.

Tabel 4. Matriks keputusan komoditas unggulan agribisnis

\begin{tabular}{llcccc}
\hline No & $\begin{array}{c}\text { Komoditas } \\
\text { Unggulan }\end{array}$ & C1 & C2 & C3 & C4 \\
\hline 1 & Kayu manis & 0,227 & 0,303 & 0,162 & 0,342 \\
2 & Kopi & 0,335 & 1,388 & 0,482 & 0,253 \\
3 & Kentang & 0,881 & 0,438 & 0,239 & 0,397 \\
4 & Cabe & 0,414 & 1,281 & 0,611 & 2,448 \\
\hline & Bobot & $\mathbf{0 , 2 3 3}$ & $\mathbf{0 , 3 3 3}$ & $\mathbf{0 , 1 6 7}$ & $\mathbf{0 , 2 6 7}$ \\
\hline
\end{tabular}

Sumber: Data diolah, 2021

Hasil penjumlahan dari matrik keputusan untuk penentuan komoditas unggulan agribisnis dipakai sebagai dasar penetapan komoditas unggulan agribisnis yang terpilih melalui proses penentuan ranking unggulan seperti yang disajikan pada tabel di bawah ini.

Tabel 5. Hasil ranking penentuan komodidtas unggulan agribisnis

\begin{tabular}{llrc}
\hline No & Komoditas unggulan & Nilai total & Ranking unggulan \\
\hline 1 & Kayu manis & 1,033 & 4 \\
2 & Kopi & 2,457 & 2 \\
3 & Kentang & 1,955 & 3 \\
4 & Cabe & 4,754 & 1 \\
\hline
\end{tabular}

Sumber: Data diolah, 2021 
Berdasarkan hasil perhitungan dengan menggunakan model SAW maka didapat komoditas unggulan agribisnis terpilih urutan pertama adalah komoditas cabe. Urutan kedua dan tiga yaitu komoditas kopi dan Kentang. Sedang kayu manis menepati urutan ke empat.

\section{Pengembangan produksi dan pemasaran komoditas unggulan agribisnis}

Pengembangan produksi dan pemasan komoditas unggulan tidak lepas dari Sarana produksi yang tersedia. Sarana produksi tersebut harus mempunyai sifat spesifik sehingga petani bisa dengan mudah menggunakan dalam rangka meningkatkan produktivitas usahataninya (Soekartawi, 2010).

Dalam menganalisis pengembangan produksi dan pemasaran komoditas unggulan agribisnis di deskripsikan dalam bentuk 2 kondisi yaitu pertama produksi dan pemasaran kondisi sekarang, kedua produksi dan pemasaran kondisi kedepan. Kedua tersebut juga dibagi atas 2 kategori komoditas unggulan agribisnis yaitu komoditas perkebunan berupa kayu manis dan kopi sedangkan komoditas hortikultura berupa cabe dan kentang.

Produksi dan pemasaran komoditas perkebunan berupa kayu manis dan kopi menyajikan tahapan yang panjang dimana terdapat 4 tahapan untuk produksi berupa budidaya, panen, pengeringan dan sortiran. Pengolahan hasil pertanian merupakan tahapan yang penting. Menurut Soekartawi (2010) pentingnya pengolahan hasil ini dikarenakan (1) meningkatkan nilai tambah, (2) Meningkatkan kualitas hasil pertanian, (3) meningkatkan tenaga kerja, (4) meningkatkan keterampilan produksen dan (5) peningkatkan pendapatan produksen

Untuk pemasaran dilakukan 3 tahapan berupa pengklasifikasian, pengumpulan dan ekspor. Khusus pemasaran kopi ditemukan pemasaran langsung pada konsumen akhir berupa bubuk kopi. Pada kondisi pemasaran terdapat juga nilai tambah terjadi pada saat pengolahan biji kopi menjadi bubuk kopi dan kayu manis menjadi bubuk kayu manis yang dilaksanakan di kota Sungai Penuh.

Berbeda dengan komoditas hortikultura berupa cabe dan kentang hanya ditemui 3 tahapan dalam produksi berupa budidaya, panen dan sortiran. Untuk pemasaran dilakukan 2 tahapan berupa pengumpulan dan pasar. Belum terlihat peningkatan nilai tambah yang dilakukan petani terhadap produk cabe dan kentang. Hasil produksi cabe dan kentang disortir guna pemilahan kualitas. Produk tersebut langsung dipasarkan ke kota Sungai Penuh atau luar kota lainnya.

Produksi dan pemasaran kedepan untuk komoditas perkebunan perlu mengikutsertakan koperasi. Peranan koperasi disini selain sebagai memberi kredit, penyedian kebutuhan produksi, juga berperan sebagai pengelolaan dan pemasaran produksi (Yuvanda. S dan Rachmad, RM, 2021). Untuk itu peranan koperasi perlu sebagai pengelola pabrik dan memasarkan produk hasil olahan. Pabrik bubuk kayu manis dan pabrik kopi yang dikelola koperasi milik petani dan pemasarannyapun wajib mengikutsertakan koperasi. Ini berarti penumbuhkembangkan koperasi produksi dan pemasaran adalah suatu kewajiban untuk meningkatkan nilai tambah dan pendapatan petani. Hal ini sejalan dengan penelitian Sibuea, M.B, (2016) yang menyatakan bahwa layanan kredit dan pemasaran produksi yang dilakukan oleh koperasi berpengaruh terhadap pendapatan petani anggota koperasi.

Produksi dan pemasaran kondisi kedepan yang diinginkan untuk komoditas hortikultura khusus cabe dan kentang juga harus mengikutsertakan koperasi. Koperasi harus mengelola pasar agribisnis dan pasar melalui internet (e-farmer dan e-tani). Kehadiran koperasi dapat mendorong peningkatan pendapatan petani. Petani melalui koperasi harus mengelola sendiri pasar agribisnis dan mengakses e-cormmece 
komoditas hortikultura cabe dan kentang dapat dipasarkan langsung pada konsumen akhir melalui koperasi.

\section{KESIMPULAN DAN SARAN}

\section{Kesimpulan}

Komoditas unggulan agribisnis yang terpilih yaitu komoditas Cabe ranking pertama, Kopi ranking kedua, Kayu Manis ranking Ketiga dan Kentang ranking yang keempat.

Produksi dan pemasaran kondisi sekarang terlihat petani perkebunan maupun hortikultura tidak ada peningkatan nilai tambah dan peran koperasi. Sedangkan produksi dan pemasaran kedepan yang diinginkan maka harus dilaksanakan peningkatan nilai tambah dan penguasaan pasar melalui koperasi. Khusus untuk komoditas hortikultura kedepan diinginkan juga peran koperasi perlu mengusai pasar agribisnis dan pasar melalui internet.

\section{Saran}

Guna meningkatkan produksi 2 komoditas hortikultura (cabe dan kentang) harus dilaksanakan perluasan areal tanam karena potensi yang belum digarap masih besar. Perlu pula itu juga dibangun pusat pembibitan unggul untuk mendapatkan bibit cabe dan kentang yang unggul.

Perlu dilakukan pengembangan koperasi produksi dan pemasaran milik petani. Pengelola koperasi wajib menguasai teknologi pengolahan dan pemasaran melalui internet untuk meningkatkan nilai tambah.

\section{DAFTAR PUSTAKA}

Arsyad, L. (2005). Pengantar perencanaan pembangunan ekonomi daerah (Edisi 1, cetakan 1, BPFE Yogyakarta: Yogyakarta.

Harinta, Y.W., Basuki, J.S., dan Sukaryani, S. (2018). Pemetaan dan pengembangan agribisnis komoditas unggulan sayuran di Kabupaten Karanganyar. Jurnal Agriekonomika 7(1), 37-45

Kartasapoetra, G, (2000). Makro ekonomi. edisi kedua, cetakan keempat belas. Raja Grafindo Persada: Jakarta

Kusumadewi, S. Hartati, S., Harjoko, A., Wardoyo, R., (2006). Fuzzy multy atribut decision making (Fuzzy MADM). Graha Ilmu: Yogyakarta

Sibuea, M.B. (2016). Peranan koperasi dalam kegiatan usaha tani di kabupaten langkat. proceding of CMR. International Conference on Mutidisciplinary Research, 1(1), $189-196$

Soekartawi. (2010). Agribisnis: teori dan aplikasinya. PT. Raja Grafindo Persada: Jakarta

Watemin dan Putri, R.H. (2016). Keunggulan komperatif komoditas hortikultura di kawasan Agropolitan Kecamatan Belik. Agriekonomika. 5(2).170-176

Yuvanda, S., dan Aisyah, D.R Nur. (2021). Penentuan industri kecil pangan unggulan dengan Metode SAW dan dampaknya terhadap tenaga kerja di Kota Jambi. Jurnal Paradigma 16(2), 279-284

Yuvanda. S dan Rachmad, M.R (2021). Konsepsi pengembangan koperasi. Fakultas Ekonomi dan Bisnis. Universitas Jambi: Jambi 